\title{
A Collection of Economic and Social Data from Glitch, a Massively Multiplayer Online Game
}

Peter M. Landwehr

March 5, 2013

CMU-ISR-13-100

Institute for Software Research

School of Computer Science

Carnegie Mellon University

Pittsburgh, PA 15213

\section{Contact Information}

plandweh@cs.cmu.edu

CASOS technical report.

This work was supported in part by the Office of Naval Research (N00014-06-1-0104) for adversarial assessment, and (1193343 with UCSD) for massively multiplayer online games (MMOG) - social and cultural model embedding technologies. Additional support was provided by CASOS — the center for Computational Analysis of Social and Organizational Systems at Carnegie Mellon University (http://www.casos.cs.cmu.edu/). The views and conclusions contained in this document are those of the authors and should not be interpreted as representing the official policies, either expressed or implied, of the Office of Naval Research, or the U.S. government. 
Keywords: virtual currency, online game, Glitch, social network, economics, video games, online forum, social media. 


\begin{abstract}
This report presents a collection of data describing many of the economic and social interactions that occurred in Glitch, a recently closed massively multiplayer online game aimed at casual players. The bulk of the data are records of sales of virtual goods by different players during the game's life, stored as CSV files. The records depict a history of the Currant, the game's principal currency. The data also includes both a snowballsample based scrape of all of the explicit friendships between different players (where "friendships" are minimally defined relationships that players may create for any reason) and a scrape of the seven different Glitch forums. This scrape is presented as both raw HTML and in a minimally parsed format sufficient for generating a basic network of posters and responders, while poster and responder networks are provided in DyNetML format. The friendship network is provided as both a CSV and a DyNetML file.
\end{abstract}





\section{Table of Contents}

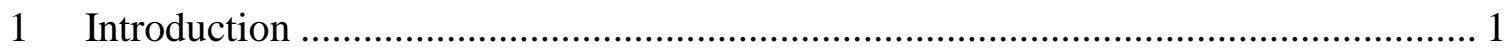

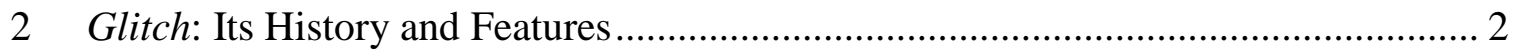

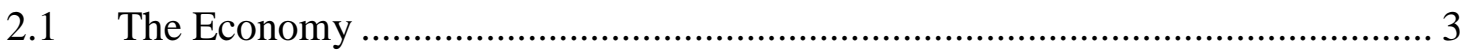

2.2 Interactions Outside of the Game................................................................ 4

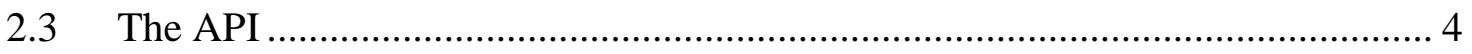

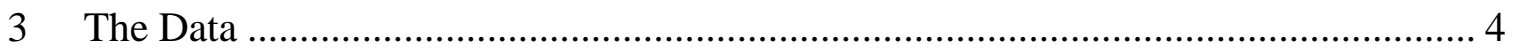

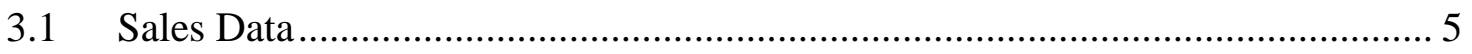

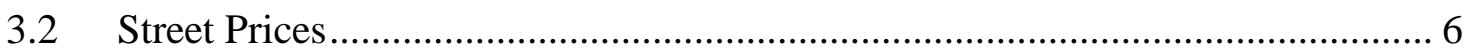

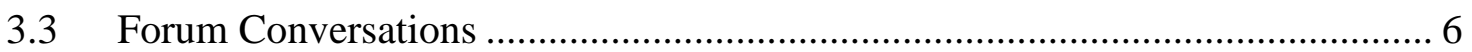

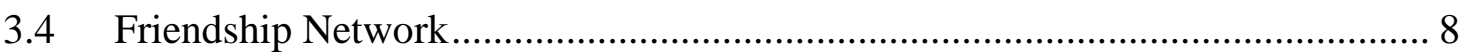

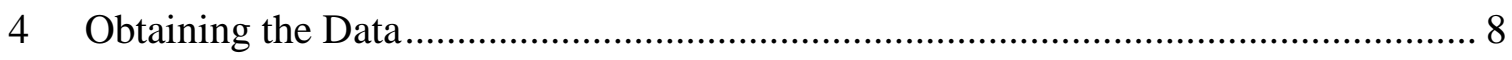

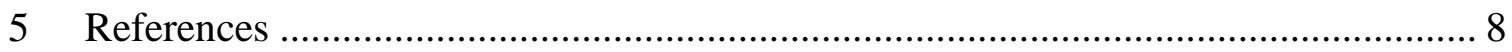





\section{Introduction}

The Glitch Dataset consists of four different archives of data related to the online game Glitch: [1]

- A history of sales between different players

- A record of the official prices of many in-game items, as set by Tiny Speck, the game's developer.

- A snapshot of the stated friendships between many of the game's players

- A scrape of the threads in the game's forum, preserved as both raw HTML and a parsed CSV that can be used to make networks of posts and responses and posters and responders.

I began collecting auction data almost immediately after the game's release, and continued through the game's closure. In late July of 2012 I scraped the game's forums and used both that scrape and my current auction data to collect a copy of the game's friendship network by scraping players' profile pages. After the game closed, I again scraped the game's forums and produced the included forum digest.

My collection was motivated by the variety of work that has been done looking at virtual economies and their parallels to economic activity in the real world. I trace this work back to Castronova's study of Everquest, in which he placed real world prices on a variety of virtual goods. [2, 3] However, players and designers have been negotiating the difficulties of virtual economics since at least Lucasfilm's Habitat in 1986. [4, 5] Interest in social activities in virtual worlds dates back to at least Bartle's characterization of MUD2's players, [6, 7] while Dibbel provided a useful journalistic perspective on LambdaMOO in his book My Tiny Life. [8, 9]

Since this early work, much has changed. Popular press articles and books have been written on the practice of using sweatshop labor and AIs to harvest and resell virtual currency, while journal articles have been authored on how to prevent the practice. Many games have adopted "freemium" models, in which much of the content is now free but some portion can be purchased for real money. Reports from the World Bank and the University of Helsinki have examined the potential of monetizing virtual spaces, [10, 11] and freemium models have been debated in Gamasutra, a lead industry trade paper. [12], [13] Many papers and books have been written profiling different communities of players and examining parallels between virtual world and real world organizations. [14]-[20] EVE Online now provides quarterly updates on its in-game economy. [21], [22] By understanding a virtual currency's dynamics it may be possible to understand how to monetize it or -more critically- how to make people want to and enjoy participating in it. I am publishing the Glitch data, in hopes that researchers will be able to better understand the dynamics of virtual currencies relative to real currencies and to better design virtual currencies and game dynamics that accommodate them.

In section 2 of this report, I provide a basic description of the game's history and a description of the game's features relevant to understanding the data. For a more thorough description, individuals should consult Tiny Speck's official encyclopedia. [23] In section 3 I describe the data, and discuss a few potential applications for it. In section 4 I discuss the process for obtaining the data. 


\section{Glitch: Its History and Features}

Glitch was a flash-based, freemium MMO aimed primarily at social players. Tiny Speck Incorporated began developing the game in 2009, and alpha testing began occurring in February of 2010. [24], [25] The game entered Beta in April of 2011, [26] and officially opened on September 27, 2011. The game was met with a mix of positive and negative reviews, alternately criticizing it for not providing players with anything to do and praising it for its lack of structure. [27]-[30] Citing several design issues, Tiny Speck "unlaunched" the game on November 30, 2011 for retooling. [31] It remained playable, and during the course of this second Beta Tiny Speck introduced a variety of experimental design changes. On November 14, 2012, Tiny Speck announced that Glitch would be closing on December 9, 2012. [32], [33] In the wake of the announcement, various critical outlets revisited the game to try and summarize its nature and the reasons for its closure. Stewart Butterfield, the lead developer, attributed the game's difficulties to both new players having a hard time knowing what they were "supposed" to do and, more fundamentally, being tied to Adobe Flash as a platform and thus having limited possibilities for mobile development. [34]-[37]

While short lived and not broadly successful, Glitch had a passionate following among many players who remained committed to the game throughout its life. Glitch was also considered by industry to be novel and well-crafted, getting nominated for two Game Developers Choice Online Awards for both art and game design. [38]

Glitch featured a colorful environment, 2D avatars, a variety of predefined virtual items that players could craft, consume, and cultivate, and a large set of locations to explore. The game was set in the collective dreams of eleven sleeping giants, and the game world was infused with a corresponding sense of whimsy. Grain was harvested from chickens, while eggs came from egg plants. Players cooked using Famous Pugilist Grills, and earned achievements for greeting other players and performing certain activities a prime number of times. Gameplay centered on the crafting of goods and cultivation of crops, chat, carrying out quests, creatively interacting with other players and the environment, and designing and improving one's home. (The nature of players' personal property changed significantly over the game's life. All versions of the home have afforded some degree of decoration and the ability to show one's home off to other players.) Quests generally required players to make or cultivate particular items, interact with other players, or seek out mysterious phenomena. Quests could not be sought out, but were doled out to players at periodic intervals or when they arrived at certain locations.

Like many MMOs, Glitch incorporated levels and experience points, but decoupled in-game skills from experience in a move similar to that used by EVE Online. [21] EVE is a "hard-core" MMO in which limited resources and economic tension drive the game forward, and is known for having long maintained a devoted block of players. In Glitch, as in $E V E$, players choose a skill to train and then wait the required number of hours until it has been learned. Skills allow players to craft objects or perform actions that they could not otherwise carry out, or to simply perform a particular set of actions more quickly. Time-based learning discourages players from grinding tasks to improve their abilities, though they may continue to grind for other reasons. Experience points were eventually removed in favor of Imagination (iMG), one of three currencies in Glitch. 


\subsection{The Economy}

Glitch initially supported two currencies, credits and currants. During the course of development a third currency, imagination (iMG) was added. Credits were used by players to purchase various luxury items in-game, such as furniture and wallpaper for their houses, tokens for fast transportation to different locations, and clothes for their avatars; these items could often only be obtained by paying with credits.. While players begin the game with a token number of credits, they can only be obtained through real money transactions. Credits had no economic value in Glitch, but were of critical importance to Tiny Speck as a method for generating profit. Credits could not be exchanged with other players, and items purchased with credits could not be sold to other players.

Imagination (iMG) was introduced in May of 2012 as a replacement for experience points. [39], [40] Players could collect it as they used to experience points: by finding it in different locations, using certain items, completing quests, or maintaining their homes. iMG could be spent on a variety of upgrade cards that would improve your rewards for carrying out different actions in-game. These cards were made available to individual players in randomized batches, so the bonuses were less ubiquitous than those provided by leveling skills. While iMG could not be used to purchase items from other players, certain upgrade cards that transport a player to a different location could be sold to other players.

Currants are the baseline currency of the game. As with iMG, currants could be found in different locations and rewarded for completing particular quests. Players could also get currants by selling goods back to vendors directly. Vendors would pay a portion of the current 'street price' of the item, a value set by Tiny Speck and that floated during the course of the game; the player-curated wiki reports the resell price as being $70 \%$ of the stated street price. [41]

Like many other MMOs, Glitch also permitted players to buy and sell items within the game for their own interests. Sales of goods might be motivated by any number of social reasons. From the standpoint of the game's mechanics, Glitch demanded that players periodically eat virtual food in order to maintain their energy levels. More sophisticated food would restore more energy, but would also require more energy to prepare. That said, many of the highest values sold in the game were toys, rare artifacts, and items that had been officially removed. For example, the game initially permitted players to grow

strawberries. When strawberries were removed from play, the remaining strawberry seeds -no longer able to grow crops- were quite valuable.

Players had three ways to sell items: auctions, private arrangement, and Storage Display Boxes (SDBs). Auctions existed since the beginning of the game, and resemble the auctions in other MMOs - that is to say, they are not actually auctions but rather classified ads. Players could choose to place any number of a particular item on sale, as well as see all of the other prices on offer. They could also see the current lowest price of an item on offer, allowing them to easily lowball other players. Postings expired after three days, and Tiny Speck would claim a small fee for each posting. Initially listing an auction cost a 3\% fee, followed by an 8\% commission fee. On May 25, 2012 commissions on auctions were dropped and listing fees were adjusted upward to 7\%. [42] Players could also sell games via private arrangement. For unknown reasons, players began posting lists of items that they wanted to buy and sell to the game's main forum as opposed to posting them in auctions. To confront bloat in the forum, Tiny Speck created a specific "Marketplace" forum in December 2011. [43] Players also arranged sales in in- 
game chat, and in May of 2012 Tiny Speck introduced a dedicated chat channel for conversations related to trading and sales. [44]

The last method by which players could sell goods was via Sales Display Boxes (SDBs). On In April of 2012 Tiny Speck revamped Glitch's housing system to provide players with a variety of decorating alternatives. Included in this update were SDBs, boxes in which players could store and display particular items in their homes; if a player had a set of particularly rare items, for example, they might display them in this way. SDBs could also be used to sell goods, by assigning a particular cost to items. With this update, players began to compile detailed lists of streets on which particular goods could be bought and sold. [39]

\subsection{Interactions Outside of the Game}

In addition to the game content, Tiny Speck created an internal social network for players, accessible via the web. All players had profile pages to which they could post status updates, friend other players in order to see their updates, and join particular player groups. (These choices also had in-game functions a well - players could track their friends and privately chat with them, or follow dedicated discussion channels belonging to a particular community.) Players could also take screenshots in the game and then post and comment on them using this social network.

As mentioned above in the discussion of private sales, the game supported a forum with five different categories at close: Announcements, General, Ideas, Marketplace, Bugs, and Off Topic. Posts were sorted most recent to least recent, and were posted with their age relative to the present ("Posted 32hr ago"). As posts aged, the backdating become more general: minutes, to hours, to days, to weeks, to months, to years, to "a long time ago" (more than three years). When players joined an online group, they also got access to that group's forum and could post to it as well.

\subsection{The API}

Tiny Speck created a public API for Glitch to make it easy for developers to create tie-in products and services; they also maintained a separate forum specifically for discussion of the API. Example uses included services for monitoring current auction prices and websites monitoring the distribution of resources at different locations. Because the game largely functioned through web pages, developers also created a mix of Javascript addons that did not leverage the API but provided useful information to players.

\section{The Data}

The Glitch Dataset consists of four components, provided as zipped CSV files: records of posted and completed sales, street price references collected at the end of the game, records of conversations posted to the forum, and a network of stated friendships between players.

All data were collected via a mix of python scripts that called the game's API and/or scraped HTML from game-related websites using Curl. I cleaned raw HTML using the BeautifulSoup library for Python; data obtained through the API did not need cleaning. 


\subsection{Sales Data}

Using a framework of Python scripts and API calls, I authored a program that scraped auctions, verified their status when they ended, and archived them on a MySQL server. This system ran largely continuously between November 17, 2011, and December 10, 2012. Several intervals were lost due to my processing computer running out of disk space before old auctions could be archived and purged.

The program scraped the posted list of active auctions once every ten seconds. When parsed, auctions were added to a MySQL database. Those that had been seen to disappear from the list of active auctions had their current status verified against the webpage for the specific auction. For each individual auction, I have the following data:

- player: An identifier for the player who posted the auction

- created: The date and time the auction was created

- expires: The date and time the auction was scheduled to end

- disappeared: The date and time the auction disappeared from my records

- class_tsid: The unique name of the object being auctioned. Note that the unique identifier may differ from the name of the object as it appeared in the game. For example: "Bushel of Grain" is logged as grain_bushel. Additionally, several items were renamed over the course of the game. An antidote to Tree Poison was initially listed as "tree_poison_antidote", but then updated to "potion_tree_poison_antidote". (All potions were recoded to have a "potion_" prefix.) The original items were still available, but classified as rare and often priced by players accordingly.

- category: The category of the object. Categories provided a general method for sorting items that might be related. Certain categories were retired during the course of the game, while others were introduced; at the end of November, 2011, the "seed" category was merged into the more general "crops_herbs_seeds_beans". Items also had their category changed: all_spice was variously categorized as "basic_resource","food", and "spice", though all three categories existed throughout the game.

- count: the number of objects sold.

- tool_uses: Certain items, such as tinkertools or fertilidust, could be used several times before they needed to be repaired or were destroyed. This category lists the number of uses that a tool had remaining.

- tool_capacity: The maximum number of times the particular item could be used.

- state_id: The final state of the auction: 1 indicates that the auction is active, 2 that the auction ended in a sale, 3 that the auction was canceled, and 4 that the auction is expired. As the auction system was shut down while some sales were open, 1105 auctions remain listed as active despite being impossible to end.

After the introduction of SDBs, Tiny Speck updated the API to provide information about SDB sales and price changes. I modified my own code to support collecting data about SDBs correspondingly, and as such can provide a record of all SDB sales between September 9, 2012, and December 9, 2012. Because the API call that covers SDB sales 
differs from that employed for auctions, the amount of data collected is unfortunately less. The SDB data has these fields:

- $\quad$ sold: The date and time of the sale

- class_tsid: The unique name of the sold object

- count: The number of objects sold

- cost: The number of currants charged

The dataset contains a total of 2914359 auctions and 403623 SDB sales.

\subsection{Street Prices}

The street prices of the different objects were periodically updated by Tiny Speck. These prices provide a baseline for what a vendor might charge for a good. (Many items with base prices could not be purchased from vendors.) If a player took an item to a vendor, they would be paid $70 \%$ of the item's stated street price. This data contains two fields:

- class_tsid: The unique name of the sold object

- price: The street price of the object

The list contains 560 items with street prices. The sales data contains 742 items. Items without street prices include both objects that have been removed from the game and rare objects that were never added to the official encyclopedia of Glitch items. This street price list was scraped on December 11, 2012, after the game had closed, and as such represents Tiny Speck’s final assessment of the street prices of items.

\subsection{Forum Conversations}

I scraped the contents of the main Glitch forums on December 12, 2012, and the developer forum on December 14, 2012. In the aftermath of the game's closure, the main forums have remained busy with players discussing life and where they will take their activities in the future. The primary issue encountered scraping the data was that because the forum was being actively used as the scrape was taken, some comments were lost. This is represented in the raw HTML by seeing the same comment repeated on multiple pages. The Glitch Dataset includes both the raw HTML of all of the threads recovered during the scrape and several formatted files compiling aggregate information about posts and suitable for calculating some summary statistics.

There are seven forums affiliated with the game: Announcements, Bugs, Developer, General, Ideas, Marketplace, and Offtopic. The Developer forum was placed separately from the others, in the section of the site dedicated to problems with and requests for changes to the API. All threads from a particular forum are stored in a dedicated folder. Each scraped HTML file is labeled as: $<$ Thread Id $>$ page $<$ page number $>\#<$ timestamp $>$.html

Individual forum digests are stored in files that include these fields: 
- post: A unique identifier for the thread

- category: 'player' or 'staff', depending on if the post was made by a player or by a member of Tiny Speck. Note that some players eventually became staff at Tiny Speck; the category label reflects their role at the time of the post.

- comment: A unique identifier for the comment. If this value equals 'post', this is the root post of the thread

- user: A unique identifier for the user. Comments made by users who later deleted their accounts have had attributions purged from the website, and their comments are attributed to 'DELETED'.

- date: description: the descriptive text present on the page when it was scraped. (e.g. "7 months ago")

- earliest: The earliest possible date for the post

- latest: The latest possible date for the post

The values for earliest and latest are derived partly from the date description and partly that, because the threads were actively growing as they were being scraped. If a comment was seen twice, the first latest and second earliest values are retained. Summary statistics derived from the digests are presented in the table below.

\section{Forum Total threads Responses in threads Players who used the forum}

\begin{tabular}{lrrr}
\hline Announcements & 416 & 8150 & 2046 \\
Bugs & 4389 & 13957 & 2980 \\
General & 12323 & 209874 & 8555 \\
Ideas & 8009 & 40669 & 4264 \\
Marketplace & 3691 & 16485 & 1764 \\
Off topic & 958 & 18713 & 2269 \\
Developer & 188 & 739 & 188
\end{tabular}

In addition to HTML and digest files, I have also derived a set of networks for each forum. The networks are are in DyNetML format, an XML variant used by the ORA network analysis program developed by CASOS and CarleyTech. Each DyNetML network contains three node classes, one for players, one for posts, and one for replies. They also contain four networks: one linking repliers to posters, one from players to posts, one from players to replies, and one from replies to posts. Each post and reply has been assigned a "Role When Posted" attribute of "Player" or "Staff” for whether or not the player who made the post was a player or staff member. Correspondingly, each player has a "Role" attribute with value "Player", "Staff", and "Player and Staff" for whether they were a player, staff member, or one of the 35 players who also posted as a member of Tiny Speck’s staff. 


\subsection{Friendship Network}

As noted earlier, friending another player was a minimal commitment in Glitch and its interpretation was left up to the player. From a gameplay perspective, being someone's friend made it easier to locate someone in the game, communicate with them, or visit their house. The friendship network data contains a snowball-scrape of the Glitch network, taken in early July of 2012. The center of the snowball is a list of all of the players who posted auctions at some point in time and a collection of players who had posted in the forum. Friendships were not required to be mutual.

The network is included as both a CSV and a DyNetML file, and contains 62060 players and 492679 distinct friendship links. As with the forum networks, the players in the DyNetML network have been assigned attributed based on if they were strictly players, members of Tiny Speck's staff, or were at one point players and at other times members of the staff. However, because the attribute data is derived from forum participation information, only 8810 players could have this attribute assigned.

\section{Obtaining the Data}

The Glitch Dataset can be obtained in several ways. A copy of the data will be posted to the CASOS lab website at http://www.casos.cs.cmu.edu. A copy of the data will also be archived by the Institute for Software Research at Carnegie Mellon. A copy of the data and this report will be stored at my personal website, http://www.doeverythingforever.com and will be available by contacting me directly, at plandweh@cs.cmu.edu or via the website.

\section{Citation}

If using the Glitch Data, please cite this tech report, as follows:

P. M. Landwehr, "A Collection of Economic and Social Data from Glitch, a Massively Multiplayer Online Game," Carnegie Mellon University, Pittsburgh, Pennsylvania, USA, Technical Report CMU-ISR-13-100, 2013 http://reports-archive.adm.cs.cmu.edu/anon/isr2013/abstracts/13$\underline{100 . h t m l}$

\section{References}

An important note regarding references: on February 25, 2012, Tiny Speck announced that it would be taking significant portions of the Glitch website offline, including the forums. [45] As such, many of the forum posts referenced below are no longer directly available on the web. Users should be able to find some of them within the raw HTML of the forum dump included in the dataset. They may be able to find others in the Internet Archive, located at http://www.archive.org. 
[1] Tiny Speck Incorporated, Glitch. San Francisco, California: Tiny Speck Incorporated, 2012.

[2] 989 Studios, Verant Interactive, and Sony Online Entertainment, EverQuest. Sony Online Entertainment, 1999.

[3] E. Castronova, "Virtual Worlds: A First-Hand Account of Market and Society on the Cyberian Frontier," Cal State Fullerton, 1, Dec. 2001.

[4] C. Morningstar, F. R. Farmer, Lucasfilm Games, Quantum Link, and Fujitsu, Habitat. Lucasfilm Games, 1986.

[5] F. R. Farmer and C. Morningstar, "The Lessons of Lucasfilm's Habitat," in Cyberspace: First Steps, M. Benedikt, Ed. Cambridge, MA: MIT Press, 1990.

[6] R. A. Bartle, MUD2. Colchester, Essex, UK: MUSE Limited, 1985.

[7] R. A. Bartle, "Players Who Suit MUDs," Players Who Suit MUDs, 1996. [Online]. Available: http://www.mud.co.uk/richard/hcds.htm. [Accessed: 24-Jun-2009].

[8] P. Curtis, LambdaMOO. Palo Alto, California: Xerox PARC, 1990.

[9] J. Dibbell, My Tiny Life, Second. United States: Henry Holt and Company, 1999.

[10] V. Lehdonvirta and M. Ernkvist, "Knowledge Map of the Virtual Economy: Converting the Virtual Economy into Development Potential,” infoDev/World Bank, Washington, DC, Apr. 2011.

[11] "Acquisition, Retention and Monetization in Social and Virtual Spaces (ARMS): Project Final Report," Helsinki Institute for Information Technology / University of Turku, Helsinki, Finland, Apr. 2012.

[12] T. Gaulton, “Opinion: Embrace Freemium,” Gamasutra, 16-May-2012. [Online]. Available:

http://www.gamasutra.com/view/news/170350/Opinion_Embrace_freemium.php.

[13] D. T. York, “Opinion: The principles of game monetization," Gamasutra, 16-Feb2012. [Online]. Available:

http://www.gamasutra.com/view/news/129663/Opinion_The_principles_of_game_m onetization.php.

[14] N. Ducheneaut, N. Yee, E. Nickell, and R. J. Moore, "The life and death of online gaming communities: a look at guilds in world of warcraft," in $\mathrm{CHI}$ '07:

Proceedings of the SIGCHI conference on Human factors in computing systems, New York, NY, USA, 2007, pp. 839-848.

[15] N. Ducheneaut, N. Yee, E. Nickell, and R. J. Moore, “'Alone together?': exploring the social dynamics of massively multiplayer online games," in $\mathrm{CHI}$ '06:

Proceedings of the SIGCHI conference on Human Factors in computing systems, New York, NY, USA, 2006, pp. 407-416.

[16] Y. B. Kafai, "World of Whyville: An Introduction to Tween Virtual Life," Games and Culture, vol. 5, no. 1, pp. 3-22, Jan. 2010.

[17] M. Jakobsson and T. L. Taylor, "The Sopranos Meets EverQuest: Social Networking in Massively Multiplayer Online Games," in Proceedings of DAC 2003, Melbourne, Australia, 2003, pp. 81-90.

[18] C. Pearce and Artemesia, Communities of Play: Emergent Cultures in Multiplayer Games and Virtual Worlds. MIT Press, 2009.

[19] B. Nardi and J. Harris, "Strangers and friends: collaborative play in world of warcraft," in Proceedings of the 2006 20th anniversary conference on Computer supported cooperative work, Banff, Alberta, Canada, 2006, pp. 149-158. 
[20] H. G. Corneliussen and J. W. Rettberg, Eds., Digital Culture, Play, and Identity, 1st ed. Cambridge, MA: MIT Press, 2008.

[21] CCP Games, EVE Online. Reykjavík, Iceland: CCP Games, 2003.

[22] E. Gudmundsson, "QEN: Keep on Hunting Your Enemies - It is Good for the EVE Online Economy.” 04-Apr-2011.

[23] Tiny Speck Incorporated, “Glitch Encyclopedia,” Glitch Encyclopedia, 2012. [Online]. Available: http://www.glitch.com/encyclopedia/.

[24] D. Terdiman, "Watching the birth of Flickr co-founder's gaming start-up," CNet, 09-Feb-2010. [Online]. Available: http://news.cnet.com/8301-13772_3-1044845952.html.

[25] D. Terdiman, “The back story on Glitch’s back stories,” CNet, 10-Feb-2010. [Online]. Available: http://news.cnet.com/8301-13772_3-10450332-52.html.

[26] S. Butterfield, “Road to Beta, Chapter X: Hey! Beta is Actually Starting!,” Glitch Blog. 12-Apr-2011.

[27] T. VanDerWerff, “Glitch,” A.V. Club. [Online]. Available: http://www.avclub.com/articles/glitch,63433/.

[28] A. Smee, “Wot I Think: Glitch,” Rock, Paper, Shotgun. 04-Oct-2011.

[29] K. Adams, "Glitch, for tree-huggers and chicken-squeezers," CNet, 12-Dec-2011. [Online]. Available: http://news.cnet.com/8301-17938_105-57340528-1/glitch-fortree-huggers-and-chicken-squeezers/.

[30] B. Hindman, "Rise and Shiny recap: Glitch,” Massively. 09-Oct-2011.

[31] S. Butterfield, “The Big Unlaunching,” Glitch Blog. 30-Nov-2011.

[32] J. Olivetti, “Glitch closing down, cites limited audience,” Massively. 14-Nov2012.

[33] Tiny Speck Incorporated, “A Sad Announcement from Tiny Speck,” Glitch. [Online]. Available: http://www.glitch.com/closing/.

[34] B. Hindman, "MMObility: Why the closing of Glitch matters," Massively. 23Nov-2012.

[35] T. VanDerWerff, “A Kinder, Loving World,” The Gameological Society, 17-Dec2012. [Online]. Available: http://gameological.com/2012/12/a-kinder-loving-world/.

[36] C. Nutt, "The story of Glitch: Why this odd MMO is shutting down," Gamasutra, 30-Nov-2012. [Online]. Available:

http://www.gamasutra.com/view/news/182287/The_story_of_Glitch_Why_this_odd_ MMO_is_shutting_down.php.

[37] L. Blackwell, “This is how you shut down your MMO's servers for good: Glitch's graceful exit,” PC World, 10-Dec-2012. [Online]. Available: http://www.pcworld.com/article/2019337/this-is-how-you-shut-down-your-mmosservers-for-good-glitchs-graceful-exit.html.

[38] Game Developers Conference, “Third Annual Game Developers Choice Online Awards,” 10-Oct-2012. [Online]. Available:

http://www.gdconlineawards.com/archive/gdcoa_3rd.html.

[39] S. Butterfield, "Progress Report: April Releases,” Glitch Blog. 16-Apr-2012.

[40] Argentscarf, Liridona, Jowwus, MissCaiia, Riscy, A Ziffel, Liza Throttlebottom, and Madzapan, "Imagination," Glitch Strategy, 06-Jul-2012. [Online]. Available: http://www.glitch-strategy.com/w/index.php?title=Imagination\&oldid=32000. 
[41] Chaosphere, "Street price," Glitch Strategy, 18-Oct-2011. [Online]. Available: http://www.glitch-strategy.com/w/index.php?title=Street_price\&oldid=24401.

[42] Tiny Speck Incorporated, "Second: auction commissions...," Glitch Change Log. 25-May-2012.

[43] Blanky, "New: The Marketplace Forum," Glitch General Forum, Dec-2011. [Online]. Available: http://www.glitch.com/forum/general/14937/.

[44] K. "kevbob” Collins, "New upgrade: Trade Channeling!,” Glitch General Forum, May-2012. [Online]. Available: http://www.glitch.com/forum/general/24356/.

[45] Stoot Barfield, “The End of the Line,” Glitch General Forum, 25-Feb-2013. [Online]. Available: http://www.glitch.com/forum/general/30691/. 
Institute for Software Research • Carnegie Mellon University • 5000 Forbes Avenue • Pittsburgh, PA 15213-3890 